ASTHMA

\title{
A novel tissue inhibitor of metalloproteinase-1 (TIMP-1) polymorphism associated with asthma in Australian women
}

\author{
F Lose, P J Thompson, D Duffy, G A Stewart, M-A Kedda
}

Thorax 2005;60:623-628. doi: 10.1136/thx.2004.026930

See end of article for authors' affiliations

Correspondence to:

A/Prof P J Thompson,

Asthma and Allergy

Research Institute, QEII

Medical Centre, Nedlands,

WA 6009, Australia;

aari@aari.uwa.edu.au

Received 10 May 2004

Accepted

30 November 2004

\begin{abstract}
Background: Airway remodelling is a characteristic feature of chronic asthma and there is evidence that an airway imbalance between levels of matrix metalloproteinase-9 (MMP-9) and tissue inhibitor of metalloproteinases-1 (TIMP-1) is associated with airway remodelling. On this basis, we hypothesised that polymorphisms in the MMP-9 and TIMP-1 genes were associated with the disease process.

Methods: A number of MMP-9 and TIMP-1 gene polymorphisms were examined in an adult white Australian population of mild $(n=259)$, moderate $(n=213)$ and severe $(n=71)$ asthmatics and nonasthmatic controls $(n=406)$ using PCR-RFLP and PCR-SSCP analyses.

Results: MMP-9 -1562C >T and 836G $>$ A (Arg279Gln) were not associated with asthma $(p \geqslant 0.15)$ or asthma severity ( $p \geqslant 0.13)$, and TIMP-1 434T $>C$ (Phe124Phe) was not associated with asthma in women $(p=0.094)$ or men $(p=0.207)$. In this population, MMP-9 $-861 C>T$ and TIMP-1 323C $>$ T (Pro87Pro) were not informative (with minor allele frequencies of $<1 \%$ ), and MMP-9 -1702 T $>$ A and TIMP-1 595C $>$ T (Ser178Phe) were not detectable. However, a novel polymorphism was detected in the TIMP-1 gene 536C $>$ T (Ile158lle) which was significantly associated with asthma in women ( $p=0.011 ; O R=5.54,95 \%$ $\mathrm{Cl} 1.66$ to 34.4$)$ but not in men $(p=1.0) .536 \mathrm{C}>\mathrm{T}$ was found to be in linkage disequilibrium with $434 \mathrm{~T}>\mathrm{C}$, and haplotype analysis supported an association with asthma $(p=0.014)$.

Conclusions: This is the first reported association between a polymorphism in the TIMP-1 gene and asthma, and supports the hypothesis that the protease/antiprotease balance has an important role in this common disease.
\end{abstract}

A sthma is a complex disease which is influenced by a number of genetic and environmental factors. Abnormal remodelling of the airway wall is a characteristic feature of chronic asthma and is a dynamic process involving extracellular matrix (ECM) production, its degradation and altered structure. ${ }^{1}$ In this regard, the matrix metalloproteinases (MMPs), a family of proteases that degrade components of the ECM, and their specific inhibitors known as tissue inhibitors of metalloproteinases (TIMPs), ${ }^{2}$ have both been shown to be particularly important in this process.

Recent studies have described an imbalance in the expression of MMP-9 (also known as collagenase type IV, collagenase type V or gelatinase B) and TIMP-1 (also known as erythroid potentiating activity (EPA) or human collagenase inhibitor) in patients with asthma, implying the importance of this protease/antiprotease interaction in asthma. MMP-9 has been shown to be increased in sputum, ${ }^{3}$ bronchoalveolar lavage fluid, ${ }^{4}$ and the subepithelial basement membrane $^{1}$ of asthma patients compared with normal subjects. Although there is some confusion as to whether TIMP-1 levels remain unaltered ${ }^{5}$ or are increased ${ }^{6}$ in asthma, it is consistently reported that the normally stoichiometric ratio of MMP-9 to TIMP-1 is altered in favour of MMP-9 in the asthmatic airway. The increased effective concentration of MMP-9 has been shown to correlate with a fall in forced expiratory volume in 1 second $\left(\mathrm{FEV}_{1}\right) .^{5}$

The MMP-9 gene is located on chromosome 20q11.2-q13.1 and contains 13 exons with a well defined promoter region. A number of polymorphisms have been described in the MMP-9 coding region and its promoter region. The $-1562 \mathrm{C}>\mathrm{T}$ MMP-9 polymorphism has been shown to result in increased MMP-9 expression ${ }^{7}$ and to be associated with coronary atherosclerosis, ${ }^{7}$ increased size of complicated coronary artery lesions, ${ }^{8}$ and emphysema. ${ }^{9}$ In contrast, fewer polymorphisms have been described in the TIMP-1 gene which has six exons and maps to Xpl1.3-pl1.23, and none have been investigated for any functional effects.

On this basis, we hypothesised that polymorphisms in the MMP-9 and, perhaps, TIMP-1 genes may be associated with asthma and/or asthma severity. We investigated this association in a large population of white Australian asthmatic patients and non-asthmatic controls.

\section{METHODS}

Subjects

A large number of patients with asthma $(n=543)$ and nonasthmatic controls $(n=406)$ participated in the association study and have been described in detail previously. ${ }^{10}$ Asthma was defined as doctor diagnosed asthma and the nonasthmatic control subjects had no history of asthma or any other chronic respiratory disease. All participants were unrelated white subjects aged between 18 and 89 years. Control subjects were recruited by random mailing and the asthma patients were similarly recruited but supplemented for the more severe patients through physician referrals. All subjects gave written informed consent and completed a comprehensive questionnaire which was used in the assessment of phenotype. Approximately $15 \mathrm{ml}$ of blood was obtained from each participant and lung function was assessed by spirometry. Assessment of atopic status was

Abbreviations: ECM, extracellular matrix; EPA, erythroid potentiating activity; $\mathrm{ESE}$, exonic splice enhancer; $\mathrm{HCl}$, human collagenase inhibitor; $\mathrm{FEV}_{1}$, forced expiratory volume in 1 second; MMP-9, matrix metalloproteinase-9; OR, odds ratio; PCR-RFLP, polymerase chain reaction-restriction fragment length polymorphism; PCR-SSCP, polymerase chain reaction-single strand conformation polymorphism; SFRS2, splicing factor, arginine/serine-rich 2; SFRS6, splicing factor, arginine/serine-rich 6; SNP, single nucleotide polymorphism; TIMP-1, tissue inhibitor of metalloproteinases-1 
Table 1 PCR primers and restriction digests

\begin{tabular}{|c|c|c|c|c|c|c|}
\hline Polymorphism & Position & Primers $\left(5^{\prime}-3^{\prime}\right)$ & $\begin{array}{l}\text { Annealing } \\
\text { temperature } \\
\left({ }^{\circ} \mathrm{C}\right)\end{array}$ & $\begin{array}{l}\text { Detection } \\
\text { method }\end{array}$ & $\begin{array}{l}\text { Restriction } \\
\text { enzyme }\end{array}$ & References \\
\hline \multicolumn{7}{|l|}{ MMP-9 } \\
\hline$-1702 \mathrm{~T}>\mathrm{A}$ & Promoter & $\begin{array}{l}\text { P13F gectggcacatagtaggecc } \\
\text { P14R cttcctagccagccggcatc }\end{array}$ & 59 & PCR-SSCP & $\mathrm{N} / \mathrm{A}$ & Minematsu et $a P$ \\
\hline$-1562 C>T$ & Promoter & $\begin{array}{l}\text { P13F gectggcacatagtaggecc } \\
\text { P14R cttcctagccagecggeatc }\end{array}$ & 59 & PCR-RFLP & Fokl & Minematsu et $a^{P}$ \\
\hline$-861 \mathrm{C}>\mathrm{T}$ & Promoter & $\begin{array}{l}\text { P9F gtgacataatcatggctcac } \\
\text { P1OR cttcctctccctgcttcatc }\end{array}$ & 53 & PCR-RFLP & Hsp92II & Minematsu et $a P$ \\
\hline $836 \mathrm{G}>\mathrm{A}(\mathrm{Arg} 279 \mathrm{Gln})$ & Exon 6 & $\begin{array}{l}\text { E6F ctcgecccaggactctacac } \\
\text { E6R gtggaggtacctcgggtcggg }\end{array}$ & 55 & PCR-RFLP & BsoBl & Minematsu et $a P$ \\
\hline \multicolumn{7}{|l|}{ TIMP-1 } \\
\hline $323 \mathrm{C}>\mathrm{T}$ (Pro87Pro) & Exon 4 & $\begin{array}{l}\text { TIF agacacttcccetcatccatc } \\
\text { TIR gaccattcccatcagagectc }\end{array}$ & 59 & PCR-SSCP & $\mathrm{N} / \mathrm{A}$ & Genbank D11139 \\
\hline 434T >C (Phel24Phe) & Exon 5 & $\begin{array}{l}\text { T2F ccaccccaattlcagtctatcg } \\
\text { T2R gtcagggtccaggcactcact }\end{array}$ & 64 & PCR-SSCP & $\mathrm{N} / \mathrm{A}$ & Genbank D11139 \\
\hline $536 \mathrm{C}>\mathrm{T}$ (lle158lle) & Exon 6 & $\begin{array}{l}\text { T3F ggggctgtcctgggctatgta } \\
\text { T3R gaggcaggcaggcaaggtgac }\end{array}$ & 58 & PCR-RFLP & Fokl & Genbank D11139 \\
\hline $595 \mathrm{C}>\mathrm{T}$ (Ser 178Phe) & Exon 6 & $\begin{array}{l}\text { T4F tcattgcttgtggacggac } \\
\text { T4R gtggacactgtgcaggctt }\end{array}$ & 54 & PCR-SSCP & N/A & Genbank D11139 \\
\hline
\end{tabular}

based on a positive skin prick reaction (weal diameter $>3 \mathrm{~mm}$ ) to at least one of five common aeroallergens: cat, dog, house dust mite, mould mix (Alternaria tenuis, Aspergillus mix, Cladosporium, Penicillin mix) and grass pollen mix (Kentucky Blue, Orchard, Red Top, Timothy, Sweet Vernal, Meadow Fescue, Perennial Rye). The study protocol was approved by the human research ethics committee of the Sir Charles Gairdner Hospital and the research ethics committee at the Alfred Hospital.

\section{Disease severity}

To assist in allocating patients to different asthma severity groups, we used criteria slightly modified from those specified by the Australian National Asthma Council ${ }^{11}$ as well as the National Asthma Education and Prevention Program (NAEPP) Expert Panel Report. ${ }^{12}$ The following variables were used to assess asthma severity: (1) lung function (\% predicted $\mathrm{FEV}_{1}$ when stable); (2) daily inhaled corticosteroid (beclomethasone equivalent) dose when stable; (3) weekly frequency of use of rescue medication over the previous 3 months; (4) weekly frequency of daytime symptoms over the previous 3 months; (5) weekly frequency of night time wakening due to asthma over the previous 3 months; (6) use of oral corticosteroids in the previous 12 months; (7) unplanned visits for asthma care to a general practitioner in the previous 12 months; (8) hospital admissions for asthma in the previous 12 months. Patients were classified as having mild, moderate, or severe asthma with respect to their score for each criterion and were placed in the overall category in which they were classified for the majority of these criteria.

\section{Selection of polymorphisms in MMP-9 and TIMP-1}

Several single nucleotide polymorphisms (SNPs) have been described in both the MMP-9 and TIMP-1 genes. For the purpose of our initial investigation into the association between SNPs in these genes and asthma phenotypes, we selected four of the five coding region polymorphisms reported by NCBI (www.ncbi.nlm.nih.gov) in the TIMP-1 gene as these may alter interactions with MMP-9, and four polymorphisms in the MMP-9 gene including one in the coding region and three promoter polymorphisms, the latter of which may be involved in altered gene expression.

\section{Molecular methods}

DNA was extracted from buffy coats using a commercially available DNA extraction kit (Qiagen, Hilden, Germany) following the manufacturer's instructions. PCR reactions were carried out in a $25 \mu \mathrm{l}$ mixture containing at final volume 100 ng genomic DNA; 10 pmol of each primer; $200 \mu \mathrm{M}$ each of dATP, dCTP, dGTP and dTTP (Promega, Madison, USA); 1-2 mM $\mathrm{MgCl}_{2} ; \quad 1 \times \mathrm{PCR}$ buffer (Qiagen); $1 \times \mathrm{Q}$ solution (Qiagen); and IU Taq polymerase (Qiagen). Amplification conditions involved denaturation of samples at $94^{\circ} \mathrm{C}$ for 5 minutes followed by 30-37 cycles of denaturation at $94^{\circ} \mathrm{C}$ for 30 seconds, annealing (temperatures detailed in table 1) for 30 seconds, and extension at $72^{\circ} \mathrm{C}$ for 30 seconds with a final extension step of $72^{\circ} \mathrm{C}$ for 10 minutes. The restriction enzymes used to characterise the MMP-9 $-1562 \mathrm{C}>\mathrm{T}$, $-861 \mathrm{C}>\mathrm{T}, 836 \mathrm{G}>\mathrm{A}$ and TIMP-1 536C $>\mathrm{T}$ polymorphisms are detailed in table 1 . Digested PCR products were electrophoresed on agarose gels (2-4\%) (Amresco, OH, USA). The TIMP-1 323C $>\mathrm{T}, 434 \mathrm{~T}>\mathrm{C}$ and $595 \mathrm{C}>\mathrm{T}$ polymorphisms and the MMP-9 $-1702 \mathrm{~T}>\mathrm{A}$ polymorphism were investigated using SSCP analysis on MDE polyacrylamide gels (BMA, ME, USA). Gels were electrophoresed at $150 \mathrm{~V}$ at $4^{\circ} \mathrm{C}$ and $24^{\circ} \mathrm{C}$, respectively, and visualised by silver staining. All samples displaying variant band patterns were sequenced to confirm genotypes. A random sample of subjects was regenotyped for all informative polymorphisms including common alleles of the TIMP-1 536C $>\mathrm{T}$ polymorphism. All rare alleles of the TIMP-1 536C $>\mathrm{T}$ polymorphism were resequenced at least twice.

\section{Statistical analysis}

Genotype and allele frequencies were calculated for each of the patient groups. Univariate comparisons of allele and genotype distribution were performed using $\chi^{2}$ tests and logistic regression analysis in the R statistics program, ${ }^{13}$ and association was assessed under a multiplicative penetrance model. Hardy-Weinberg equilibrium analysis for each group was evaluated by the exact test, implemented in the $\mathrm{R}$ statistics program. Linkage disequilibrium between the markers and associations between haplotypes and asthma were assessed using Cocaphase. ${ }^{14}$ Cocaphase uses an expectation-maximisation (algorithm) approach to establish haplotype probabilities for each person, which are applied as weights in a logistic regression association analysis. 
Table 2 Demographic data of study population

\begin{tabular}{|c|c|c|c|c|c|c|c|c|c|c|}
\hline Phenotype & $\mathrm{N}$ & $\begin{array}{l}\text { Women } \\
\text { (\%) }\end{array}$ & $\begin{array}{l}\text { Atopy } \\
\text { (\%) }\end{array}$ & $\begin{array}{l}\text { Mean (SD) } \\
\text { age } \\
\text { (years) }\end{array}$ & $\begin{array}{l}\text { Mean (SE) \% } \\
\text { predicted FEV } \\
\text { when stable }\end{array}$ & $\begin{array}{l}\text { Oral } \\
\text { corticosteroids* } \\
(\%)\end{array}$ & $\begin{array}{l}\text { Frequency of oral } \\
\text { corticosteroid use } \\
\text { (mean times/year) }\end{array}$ & $\begin{array}{l}\text { Inhaled } \\
\text { corticosteroids } † \\
(\%)\end{array}$ & $\begin{array}{l}\text { Mean (SE) inhaled } \\
\text { steroid doseł } \\
\text { ( } \mu \mathrm{g} / \text { day) }\end{array}$ & $\begin{array}{l}\text { Short acting } \beta_{2} \\
\text { adrenoceptor } \\
\text { agonists } 9 \mid \\
(\%)\end{array}$ \\
\hline Non-asthma & 406 & 56 & 51 & $50.6(14.2)$ & $101.7(2.5)$ & Nil & Nil & Nil & $\mathrm{Nil}$ & Nil \\
\hline All asthma & 543 & 63 & 83 & $49.0(15.5)$ & - & - & - & - & - & - \\
\hline Mild asthma & 259 & 61 & 84 & $47.3(15.1)$ & $92.2(1.0)$ & 5 & 1.3 & 59 & 890 (49) & 82 \\
\hline Moderate asthma & 213 & 64 & 81 & $50.8(15.9)$ & $74.2(1.4)$ & 38 & 1.5 & 95.6 & $1474.5(65)$ & 94.3 \\
\hline Severe asthma & 71 & 65 & 78 & $50.1(13.6)$ & $59.7(2.6)$ & 79 & 2.9 & 98.2 & $2729.2(165)$ & 97.5 \\
\hline
\end{tabular}

The $\mathrm{p}$ values presented are unadjusted. The haplotype analysis combines evidence from all SNPs in a gene, so tests of significance correctly adjust for the number of SNPs tested per gene. The Bonferroni corrected threshold (for an experiment-wide type I error rate of 0.05) for the haplotype tests is therefore 0.025 and the individual SNP tests of association are "protected" by the haplotype tests.

Analysis of putative exonic splice enhancer (ESE) sites The TIMP-1 gene sequence was analysed using the exonic splice enhancer (ESE) detection program ESEfinder ${ }^{15}$ in order to predict the functional significance of the novel $534 \mathrm{C}>\mathrm{T}$ polymorphism.

\section{RESULTS}

\section{Subjects}

In total, 543 patients with asthma and 406 non-asthmatic controls participated in the study. All subjects were white, and patients with asthma were further subdivided by disease severity. The demographic data of the study population are shown in table 2. All groups had similar age and sex distributions, although the asthma group as a whole had a significantly higher percentage of atopic subjects (83\%) than the non-asthmatic control group (51\%; $<<0.0001)$. Daytime symptoms of asthma occurred, on average, 3.9 times per week in individuals with mild asthma, 6.8 times per week in those with moderate asthma, and 9 times per week in

Table 3 Allele and genotype distribution in asthma patients and non-asthmatic controls

\begin{tabular}{|c|c|c|c|c|c|c|c|c|}
\hline \multirow[b]{2}{*}{ Polymorphism† } & & & & \multicolumn{2}{|l|}{ Total } & \multicolumn{3}{|c|}{ Asthma disease severity } \\
\hline & & & & Non-asthma & All asthma & Mild & Moderate & Severe \\
\hline \multicolumn{9}{|l|}{ MMP-9 } \\
\hline \multirow{6}{*}{$-1562 C>T$} & & $\mathrm{~N}$ & & 392 & 514 & 242 & 201 & 71 \\
\hline & & Genotype & $\mathrm{cc}$ & 0.74 & 0.71 & 0.76 & 0.74 & 0.66 \\
\hline & & & $\mathrm{ct}$ & 0.24 & 0.26 & 0.22 & 0.25 & 0.30 \\
\hline & & & $H$ & 0.02 & 0.03 & 0.02 & 0.01 & 0.04 \\
\hline & & Allele & C & 0.86 & 0.84 & 0.87 & 0.87 & 0.80 \\
\hline & & & $\mathrm{T}$ & 0.14 & 0.16 & 0.13 & 0.13 & 0.20 \\
\hline \multirow{6}{*}{\multicolumn{2}{|c|}{$836 \mathrm{G}>\mathrm{A}(\mathrm{Arg} 279 \mathrm{G} \ln )$}} & $\mathrm{N}$ & & 406 & 543 & 259 & 213 & 71 \\
\hline & & Genotype & AA & 0.46 & 0.43 & 0.44 & 0.43 & 0.39 \\
\hline & & & $A G$ & 0.43 & 0.43 & 0.43 & 0.44 & 0.49 \\
\hline & & & GG & 0.11 & 0.14 & 0.13 & 0.13 & 0.12 \\
\hline & & Allele & A & 0.68 & 0.64 & 0.65 & 0.65 & 0.65 \\
\hline & & & G & 0.32 & 0.36 & 0.35 & 0.35 & 0.35 \\
\hline \multicolumn{9}{|l|}{ TIMP-1‡ } \\
\hline \multirow[t]{9}{*}{ 434T $>C$ (Phel24Phe) } & Women & $\mathrm{N}$ & & 34 & 142 & 46 & 51 & 45 \\
\hline & & Genotype & $\mathrm{CC}$ & 0.27 & 0.27 & 0.28 & 0.20 & 0.33 \\
\hline & & & $\mathrm{CT}$ & 0.44 & 0.58 & 0.63 & 0.65 & 0.49 \\
\hline & & & $\Pi$ & 0.29 & 0.15 & 0.09 & 0.15 & 0.18 \\
\hline & & Allele & C & 0.48 & 0.56 & 0.60 & 0.52 & 0.58 \\
\hline & & & $T$ & 0.52 & 0.44 & 0.40 & 0.48 & 0.42 \\
\hline & Men & $\mathrm{N}$ & & 33 & 78 & 31 & 21 & 26 \\
\hline & & Allele & C & 0.49 & 0.68 & 0.52 & 0.71 & 0.69 \\
\hline & & & $\mathrm{T}$ & 0.51 & 0.32 & 0.48 & 0.29 & 0.31 \\
\hline \multirow{9}{*}{$536 \mathrm{C}>\mathrm{T}($ (le 158le) } & Women & $\mathrm{N}$ & & 221 & 350 & 166 & 138 & 46 \\
\hline & & Genotype & $\mathrm{CC}$ & 0.99 & 0.94 & 0.94 & 0.96 & 0.93 \\
\hline & & & $\mathrm{CT}$ & 0.01 & 0.05 & 0.05 & 0.04 & 0.07 \\
\hline & & & $\Pi$ & 0.00 & 0.01 & 0.01 & 0.00 & 0.00 \\
\hline & & Allele & C & 0.99 & 0.97 & 0.96 & 0.98 & 0.96 \\
\hline & & & $\mathrm{T}$ & 0.01 & 0.03 & 0.04 & 0.02 & 0.04 \\
\hline & Men & $\mathrm{N}$ & & 183 & 200 & 97 & 77 & 26 \\
\hline & & Allele & C & 0.98 & 0.97 & 1.00 & 0.97 & 0.92 \\
\hline & & & $\mathrm{T}$ & 0.02 & 0.03 & 0.00 & 0.03 & 0.08 \\
\hline
\end{tabular}




\begin{tabular}{|c|c|c|c|c|c|}
\hline A & Wild type & $\mathrm{Ha}$ & tcc & atc & $\mathrm{ccc}$ \\
\hline & & Leu & Ser & Ile & Pro \\
\hline B & Ile158Val & $\mathrm{Ha}$ & tcc & gtc & $\mathrm{ccc}$ \\
\hline & $(534 A>G)$ & Leu & Ser & Val & Pro \\
\hline$C$ & \|le158\|le & $\mathrm{Ha}$ & tcc & att & $\mathrm{ccc}$ \\
\hline & $(536 C>T)$ & Leu & Ser & Ile & Pro \\
\hline
\end{tabular}

Figure 1 Partial TIMP-1 sequence illustrating (A) the wild type sequence, (B) the previously reported 534A $>G$ (lle 158Val) polymorphism, altering a Fokl restriction enzyme recognition site (in bold) and detected by PCR-RFLP analysis, and (C) the novel 536C >T (Ile158lle) polymorphism reported in this study, which also alters the Fokl restriction enzyme recognition site.

subjects with severe asthma. Less than half the patients with mild asthma woke from sleep due to their asthma, while all patients with severe asthma woke from sleep most nights due to their asthma. Unplanned visits to the family doctor for asthma over the previous 12 months ranged from 0.51 per year in patients with mild asthma to 1.4 per year in patients with moderate asthma and 4.2 per year in patients with severe asthma. Hospital admissions over the previous 12 months occurred in less than $5 \%$ of patients with mild asthma, in $30 \%$ of patients with moderate asthma, and in $70 \%$ of patients with severe asthma.

\section{Polymorphisms}

The MMP-9 $-1562 \mathrm{C}>\mathrm{T}, \quad-861 \mathrm{C}>\mathrm{T}$ and $836 \mathrm{G}>\mathrm{A}$ (Arg279Gln) and TIMP-1 536C $>$ T (Ile158Ile) polymorphisms were investigated using PCR-RFLP analysis and the MMP-9 $-1702 \mathrm{~T}>\mathrm{A}$, and TIMP-1 323C $>\mathrm{T}$ (Pro87Pro), 434T $>\mathrm{C}$ (Phel24Phe) and 595C $>$ T (Ser178Phe) polymorphisms were investigated using PCR-SSCP analysis. Table 3 summarises the allele and genotype frequencies obtained for all polymorphisms studied.

\section{MMP-9}

$-1562 \mathrm{C}>T$ and $836 \mathrm{G}>\mathrm{A}(\mathrm{Arg} 279 \mathrm{Gln})$

All population groups were in Hardy-Weinberg equilibrium for the MMP-9 -1562C $>\mathrm{T}$ and 836G>A (Arg279Gln) polymorphisms, and there were no associations between either of the polymorphisms and asthma $(-1562 \mathrm{C}>\mathrm{T}$ and $836 \mathrm{G}>\mathrm{A}, \mathrm{p}=0.152)$, asthma severity $(-1562 \mathrm{C}>\mathrm{T}, \mathrm{p}=0.76$; $836 \mathrm{G}>\mathrm{A}, \mathrm{p}=0.31)$, or atopy $(-1562 \mathrm{C}>\mathrm{T}, \mathrm{p}=0.49 ; 836 \mathrm{G}>\mathrm{A}$, $\mathrm{p}=0.25)$. Using a multiplicative penetrance model, the odds ratio (OR) for $-1562 \mathrm{C}>\mathrm{T}$ was 1.01 (95\% CI 0.77 to 1.33 ) and 1.16 (95\% CI 0.96 to 1.41 ) for $836 \mathrm{G}>\mathrm{A}$, so we were able to exclude, with $95 \%$ certainty, true effect sizes of 1.33 and 1.41 for these polymorphisms. The MMP-9 836A $>\mathrm{G}$ and $-1562 \mathrm{C}>\mathrm{T}$ polymorphisms were in strong linkage disequilibrium $\left(\mathrm{D}^{\prime}\right.$ cases $=0.89, \mathrm{D}^{\prime}$ controls $=0.88 ; \mathrm{p}=3 \mathrm{e}-58$ ), as reported previously, ${ }^{16}$ and there was no association between asthma and MMP-9 haplotypes $(\mathrm{p}=0.62)$.

\section{$-861 C>T$ and $-1702 T>A$}

In this population the $-861 \mathrm{C}>\mathrm{T}$ polymorphism was not informative (minor allele frequency $<1 \%$ ) and the $-1702 \mathrm{~T}>\mathrm{A}$ polymorphism could not be detected using PCR-SSCP analysis.

\section{TIMP- 1}

As the TIMP-1 gene is on the $\mathrm{X}$ chromosome, the results obtained were segregated by sex.

\begin{tabular}{ll}
$\begin{array}{l}\text { Table } 4 \\
\text { asthmatic subjects } \\
\text { Distribution of TIMP-1 haplotype in }\end{array}$ \\
\hline Haplotype $^{*}$ & Frequency \\
\hline T & 0.03 \\
TC & 0.01 \\
CT & 0.55 \\
CC & 0.41 \\
\hline${ }^{*} 536 C>T / 434 T>C$ & \\
\hline
\end{tabular}

$536 C>T(I l e 158 \| l e)$

A TIMP-1 534A $>$ G (Ile158Val) exon 6 missense mutation has previously been reported in the NCBI SNP database (SNP ID: rs1803571) and shown to alter a FokI restriction site. Genotypes based upon restriction analysis of this site were confirmed by sequence analysis. However, the 534A>G polymorphism was not detected in this population. Instead, our sequence analyses revealed a $\mathrm{C}>\mathrm{T}$ polymorphism at position 536, two bases downstream of the previously described polymorphism (see fig Sl available online at http://www.thoraxjnl.com/supplemental). The novel 536C $>$ T polymorphism did not change the translated amino acid (Ile158Ile), although it altered the previously reported 534A $>$ G (Ilel58Val) FokI restriction recognition site polymorphism (fig 1). Importantly, this new polymorphism was found to be associated with asthma in women $(p=0.011)$ but not in men $(p=1.0)$, particularly in women with mild asthma ( $p=0.009$; OR 5.54, 95\% CI 1.66 to 34.4 ). The asthma population was not in Hardy-Weinberg equilibrium for this polymorphism $(p=0.001)$, possibly due to the effects of ascertainment on a trait associated locus, nor was the polymorphism associated with atopy $(\mathrm{p}=0.589)$.

Analysis of the $536 \mathrm{C}>\mathrm{T}$ polymorphism with the ESE detection program ESEfinder ${ }^{15}$ predicted alterations in ESE sites. The substitution of a C for a T nucleotide at position 536 resulted in a reduction in score value for the SC35 (also known as SFRS2; OMIM: 600813) SR protein from 4.367 to 3.483. This is a relatively large reduction. However, both scores are still significantly higher than the binding threshold for SC35 (2.385) and are therefore unlikely to result in any change in enhancer activities. In addition, the 536C $>\mathrm{T}$ substitution is predicted to result in the complete loss of an SRp55 (also known as SFRS6; OMIM: 601944) site, TCCATC, that possessed a reasonably high binding score value of 3.223 (SRp55 threshold 2.676).

\section{T >C (Phe 124Phe)}

The TIMP-1 exon 5 434T $>$ C (Phel24Phe) polymorphism ${ }^{17}$ was not found to be associated with asthma in this population (women: $\mathrm{OR}=0.73,95 \%$ CI 0.41 to 1.29 ; $\mathrm{p}=0.094$; men: $\mathrm{OR}=0.56,95 \%$ CI 0.23 to $1.38, \mathrm{p}=0.207$ ) or with atopy $(p=0.235)$. However, a $\chi^{2}$ test showed that the $434 \mathrm{~T}>\mathrm{C}$ polymorphism was in linkage disequilibrium with the novel 536C $>\mathrm{T}$ polymorphism $\left(\mathrm{D}^{\prime}\right.$ cases $=0.24$, $\mathrm{D}^{\prime}$ controls $=0 ; \mathrm{p}=0.06$ ) and, importantly, there was an association between asthma and the TIMP-1 haplotype (table 4$)\left(\chi^{2}=10.67, \mathrm{p}=0.014\right)$.

\section{C $>T$ (Pro87Pro) and 595C $>T$ (Ser 178Phe)}

The TIMP-1 323C $>\mathrm{T}$ (Pro87Pro) polymorphism was uninformative in this population (minor allele frequency $<1 \%$ ), and the 595C $>\mathrm{T}$ (Ser178Phe) polymorphism could not be detected using PCR-SSCP analysis.

\section{DISCUSSION}

Chronic asthma is characterised by abnormal remodelling and altered airway function due, in part, to altered deposition of the ECM which may arise as the result of an imbalance in 
the expression of MMP-9 and TIMP-1. This study was designed to investigate associations between several polymorphisms in the MMP-9 and TIMP-1 genes and asthma in a large population of mild, moderate and severe asthmatics and non-asthmatic controls. Most importantly, in this comprehensive study we have demonstrated a significant association between a novel polymorphism in the TIMP-1 gene (536C $>$ T (Ile158Ile)) and asthma in women, as well as an association between the TIMP-1 haplotype and asthma. While a number of polymorphisms have been described and functionally characterised in the MMP-9 gene, few have been described in the TIMP-l gene and none have been investigated for functional effects.

No associations between asthma, asthma severity, or atopy and two polymorphisms in MMP-9 $(-1562 \mathrm{C}>\mathrm{T}$ and $836 \mathrm{G}>\mathrm{A})$ and one polymorphism in TIMP-1 $(434 \mathrm{~T}>\mathrm{C})$ were detected. Although the MMP-9 promoter polymorphism $-1562 \mathrm{C}>\mathrm{T}$ has previously been shown to result in an increase in MMP-9 expression ${ }^{7}$ and to be associated with various non-asthmatic diseases, ${ }^{7-9}$ suggesting that it may be important in tissue remodelling of the ECM, we were unable to detect an association with asthma; these findings agree with studies performed in a small Eastern European population. ${ }^{18}$ However, the polymorphic $\mathrm{T}$ allele appeared to be more common in severe asthmatics although this was not statistically significant, due perhaps to the relatively small numbers in this phenotypic group. The MMP-9 catalytic region $836 \mathrm{G}>\mathrm{A}$ (Arg279Gln) missense variant was initially described in a Swedish population, ${ }^{16}$ but the allele frequencies observed in our study suggest that the $\mathrm{G}$ allele is actually the minor allele $(\mathrm{q}=0.34)$.

We did not detect the previously described TIMP-1 534A $>\mathrm{G}$ (Ile158Val) exon 6 missense mutation (SNP ID: rs 1803571) in this population. However, we did detect a novel $\mathrm{C}>\mathrm{T}$ polymorphism at position 536 of the TIMP-1 gene, and found an association between this polymorphism and asthma in women $(p=0.011)$ in our population. The silent TIMP-1 polymorphism 434T $>C$ (Phel24Phe) has been reported to be associated with abdominal aortic aneurysm in women $(p=0.002),{ }^{15}$ but we found no association between this polymorphism and asthma, asthma severity, or atopy. Importantly, we have shown that the $434 \mathrm{~T}>\mathrm{C}$ polymorphism was in linkage disequilibrium with the novel $536 \mathrm{C}>\mathrm{T}$ polymorphism $(p=0.06)$ and there was an association between asthma and TIMP-1 haplotype $(p=0.014)$, further supporting our findings of an association between a TIMP-1 polymorphism and asthma.

Until recently, polymorphisms which did not alter the amino acid sequence of a protein were considered to be of little consequence, but a number of studies have indicated that all types of variation may be important in human genetic disease. ${ }^{1920}$ The $536 \mathrm{C}>\mathrm{T}$ polymorphism is located 18 nucleotides into exon 6 of the TIMP-1 gene, the only region responsible for binding to and preventing activation of MMP-9. ${ }^{21}$ However, this variant does not alter the amino acid sequence of the TIMP-1 protein and is therefore not predicted to affect protein structure. Nevertheless, Krawczak and colleagues ${ }^{19}$ estimate that at least $15 \%$ of point mutations resulting in human genetic disease cause RNA splicing defects, possibly from the disruption of short sequences within exons known as ESE that promote splicing, ${ }^{22}$ and it has been shown that a single nucleotide substitution in an ESE can result in failure of serine/arginine-rich non-small nuclear ribonucleoprotein (non-snRNP) splice factors (the SR proteins) to recognise the ESE, leading to exon skipping. ${ }^{23} 24$ Prediction analysis of the $536 \mathrm{C}>\mathrm{T}$ polymorphism using the ESE detection program ESEfinder ${ }^{15}$ predicted alterations in an SC35 site, reducing the binding score of this protein, and the complete loss of an SRp55 site, suggesting that these changes may affect enhancer binding and hence splicing of the gene. However, while it is interesting to speculate on the functional significance of alterations to putative ESE sites, no TIMP-1 splice variants have been reported to date, and it will be important to confirm the effect of this polymorphism on TIMP-1 and its relationship to asthma. It is also worth noting that the wild type $C$ allele is conserved in both mouse and rat (Ensembl: www.ensembl.org), which may imply a functional role for this nucleotide, although it is also possible that the $536 \mathrm{C}>\mathrm{T}$ polymorphism is in linkage disequilibrium with a functional polymorphism elsewhere in the TIMP-1 gene.

Although knockout experiments in mice have provided support for a role for MMP-9/TIMP-1 imbalance in asthma, ${ }^{25}$ the physiological significance of MMP-9 and TIMP-1 in asthma has been debated for some time. Three studies, each involving more than 20 asthmatic subjects, have reported a statistically significant increase in the levels and/or activity of MMP-9 compared with controls, ${ }^{6627}$ and a number of smaller studies support these findings. ${ }^{5829}$ The main area of discrepancy between many studies on the MMP-9/TIMP-1 system and asthma involve TIMP-1 expression levels. Some groups have reported an increase in the level of TIMP-1 in asthmatic subjects, ${ }^{6}$ whilst others have observed no differences in TIMP-1 expression between asthmatics and controls. $^{5}{ }^{29}$ It has been shown that, regardless of TIMP-1 levels, the normally stoichiometric ratio of MMP-9 to TIMP-1 is unbalanced in favour of MMP-9, and this has been negatively correlated with $\mathrm{FEV}_{1}$ in asthmatics. ${ }^{6}$ It is also possible that the actual level of expression of TIMP-1 is not the most important factor in asthma. Instead, an alteration in the structure or function of TIMP-1 may be allowing uncontrolled MMP-9 activity.

In conclusion, we have investigated the association between a number of polymorphisms in both MMP-9 and TIMP-1 genes and asthma, asthma severity and atopy using a large, carefully phenotyped white Australian population. We have shown that four MMP-9 and TIMP-1 polymorphisms were not associated with asthma, but a novel polymorphism in the TIMP-1 gene (536C $>$ T (Ilel58Ile)) was significantly associated with mild asthma in women and TIMP-1 haplotypes were also associated with asthma. The functional significance of the $536 \mathrm{C}>\mathrm{T}$ polymorphism has still to be determined, but its association with asthma severity highlights the potential importance of proteases and antiproteases in this socioeconomically important disease.

\section{ACKNOWLEDGEMENTS}

The authors thank the patients who participated in this study, the NH\&MRC for financial support, the staff at the Sir Charles Gairdner and Alfred Hospitals who assisted with clinical data collection, and Penelope Worsley, Kirrily O'Hara, Bernadette Bradley and Jing Shi for preparation of DNA and technical assistance.

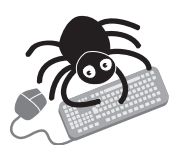

Figure S1 showing the sequence analysis of the novel $536 \mathrm{C}>\mathrm{T}$ polymorphism is available online at htp:// www.thoraxjnl.com/supplemental.

\footnotetext{
Authors' affiliations

F Lose, P J Thompson, M-A Kedda, Asthma and Allergy Research Institute and Centre for Asthma, Allergy and Respiratory Research, University of Western Australia, Perth, WA 6009, Australia

F Lose, M-A Kedda, Western Australian Institute for Medical Research and the Centre for Medical Research, University of Western Australia, Perth, WA 6009, Australia

P J Thompson, M-A Kedda, The CRC for Asthma, Australia

G A Stewart, Microbiology, School of Biomedical and Chemical Sciences, University of Western Australia, Perth, WA 6009, Australia D Duffy, Genetic Epidemiology Laboratory, Queensland Institute of Medical Research, Brisbane, QLD 4006, Australia
} 
This project was funded by the Asthma and Allergy Research Institute and the National Health and Medical Research Council of Australia

\section{REFERENCES}

1 Mautino G, Capony F, Bousquet J, et al. Balance in asthma between matrix metalloproteinases and their inhibitors. J Allergy Clin Immunol 1999; 104:530-3

2 Stetler-Stevenson WG, Krutzsch HC, Wacher MP, et al. The activation of human type IV collagenase proenzyme. Sequence identification of the major conversion product following organomercurial activation. J Biol Chem 1989;264:1353-6.

3 Vignola AM, Riccobono L, Mirabella A, et al. Sputum metalloproteinase-9/ tissue inhibitor of metalloproteinase-1 ratio correlates with airflow obstruction in asthma and chronic bronchitis. Am J Respir Crit Care Med 1998:158:1945-50.

4 Kelly EA, Busse WW, Jarjour NN. Increased matrix metalloproteinase-9 in the airway after allergen challenge. Am J Respir Crit Care Med 2000:162:1157-61

5 Cataldo DD, Bettiol J, Noel A, et al. Matrix metalloproteinase-9, but not tissue inhibitor of matrix metalloproteinase-1, increases in the sputum from allergic asthmatic patients after allergen challenge. Chest 2002;122:1553-9.

6 Hoshino M, Nakamura Y, Sim J, et al. Bronchial subepithelial fibrosis and expression of matrix metalloproteinase-9 in asthmatic airway inflammation. J Allergy Clin Immunol 1998;102:783-8.

7 Zhang B, Ye S, Herrmann SM, et al. Functional polymorphism in the regulatory region of gelatinase $B$ gene in relation to severity of coronary atherosclerosis. Circulation 1999;99:1788-94.

8 Pollanen PJ, Karhunen PJ, Mikkelsson J, et al. Coronary artery complicated lesion area is related to functional polymorphism of matrix metalloproteinase 9 gene: an autopsy study. Arterioscler Thromb Vasc Biol 2001;21:1446-50.

9 Minematsu N, Nakamura H, Tateno H, et al. Genetic polymorphism in matrix metalloproteinase-9 and pulmonary emphysema. Biochem Biophys Res Commun 2001;289:116-9.

10 Kedda MA, Shi J, Duffy DL, et al. Characterisation of two polymorphisms in the LTC4 synthase gene in an Australian population of mild, moderate and severe asthmatics. J Allergy Clin Immunol 2004;113:889-95.

11 Australian National Asthma Council. Asthma management handbook. 2002 Available at http://www.nationalasthma.org.au/.

12 National Institutes of Health. Expert Panel Report II. Practical guide for the diagnosis and management of asthma. National Asthma Education and Prevention Program. NIH publication 99-4055A. Bethesda, MD: National Heart, Lung and Blood Institute, 1997.

13 R Development Core Team. R: A language and environment for statistical computing. 2003. Available at http://www.R-project.org.
14 Dudbridge F. Pedigree disequilibrium tests for multilocus haplotypes. Genet Epidemiol 2003;25:115-21.

15 Cartegni L, Wang J, Zhu Z, et al. ESEfinder: a web resource to identify exonic splicing enhancers. Nucleic Acids Res 2003;31:3568-71.

16 Zhang B, Henney A, Eriksson P, et al. Genetic variation at the matrix metalloproteinase-9 locus on chromosome 20q12.2-13.1. Hum Genet 1999; 105:418-23.

17 Wang X, Tromp G, Cole CW, et al. Analysis of coding sequences for tissue inhibitor of metalloproteinases 1 (TIMP1) and 2 (TIMP2) in patients with aneurysms. Matrix Biol 1999;18:121-4.

18 Holla LI, Vasku A, Stejskalova A, et al. Functional polymorphism in the gelatinase B gene and asthma. Allergy 2000;55:900-1.

19 Krawczak M, Reiss J, Cooper DN. The mutational spectrum of single basepair substitutions in mRNA splice junctions of human genes: causes and consequences. Hum Genet 1992;90:41-54.

20 Cartegni L, Chew SL, Krainer AR. Listening to silence and understanding nonsense: exonic mutations that affect splicing. Nat Rev Genet 2002;3:285-98.

21 Murphy G, Willenbrock F. Tissue inhibitors of matrix metalloendopeptidases. Methods Enzymol 1995:248:496-510.

22 Blencowe BJ. Exonic splicing enhancers: mechanism of action, diversity and role in human genetic diseases. Trends Biochem Sci 2000;25:106-10.

23 Colapietro P, Gervasini C, Natacci F, et al. NF1 exon 7 skipping and sequence alterations in exonic splice enhancers (ESEs) in a neurofibromatosis 1 patient. Hum Genet 2003;113:551-4.

24 Kramer F, Mohr N, Kellner U, et al. Ten novel mutations in VMD2 associated with Best macular dystrophy (BMD). Hum Mutat 2003;22:418.

25 Cataldo DD, Tournoy KG, Vermaelen K, et al. Matrix metalloproteinase-9 deficiency impairs cellular infiltration and bronchial hyperresponsiveness during allergen-induced airway inflammation. Am J Pathol 2002;161:491-8.

26 Wenzel SE, Balzar S, Cundall $M$, et al. Subepithelial basement membrane immunoreactivity for matrix metalloproteinase 9: association with asthma severity, neutrophilic inflammation, and wound repair. J Allergy Clin Immunol 2003; 111:1345-52.

27 Oshita $Y$, Koga T, Kamimura T, et al. Increased circulating 92 kDa matrix metalloproteinase (MMP-9) activity in exacerbations of asthma. Thorax 2003;58:757-60

28 Mattos W, Lim S, Russell R, et al. Matrix metalloproteinase-9 expression in asthma: effect of asthma severity, allergen challenge, and inhaled corticosteroids. Chest 2002; 122:1543-52.

29 Belleguic C, Corbel M, Germain N, et al. Increased release of matrix metalloproteinase-9 in the plasma of acute severe asthmatic patients. Clin Exp Allergy 2002;32:217-23. 